\title{
Nanostructural studies of PVD TiAlB coatings
}

M.A. Monclus ${ }^{*}$, V. Stolojan ${ }^{2}$, C. Rebholz ${ }^{3}$, P.N. Gibson ${ }^{4}$, A. Leyland ${ }^{5}$, A. Matthews ${ }^{5}$ M.A. Baker $^{1}$

1The Surface Analysis Laboratory, School of Engineering, University of Surrey, Guildford GU2 7XH, UK.

${ }^{2}$ Advanced Technology Institute, University of Surrey, GU2 7XH, UK.

${ }^{3}$ Department of Mechanical and Manufacturing Engineering, University of Cyprus, 1678 Nicosia, Cyprus

${ }^{4}$ Institute for Health and Consumer Protection, Joint Research Centre, I-21020 Ispra (VA), Italy.

${ }^{5}$ Department of Engineering Materials, University of Sheffield, Sheffield S1 3JD, UK

\begin{abstract}
TiAlB coatings with different compositions were deposited by co-sputtering from TiAl and $\mathrm{TiB}_{2}$ targets onto AISI316 stainless steel substrates at a temperature of 170(C. The stoichiometry and nanostructure have been studied by x-ray photoelectron spectroscopy (XPS), x-ray diffraction (XRD) and transmission electron microscopy (TEM). Analysis of the XPS spectra suggests the presence of phases in agreement with the equilibrium Ti-Al-B phase diagram. Diffraction studies (XRD and TEM) indicate that coatings with $\mathrm{B} / \mathrm{Al}$ ratios ( 6 are amorphous, while coatings with $\mathrm{B} / \mathrm{Al}$ ratios ( 6 exhibit a nanocomposite structure with average $\mathrm{TiB}_{2}$ grain sizes of $\sim 2-3 \mathrm{~nm}$ for the highest $\mathrm{B} / \mathrm{Al}$ ratio of 16 . Nanocomposite coatings show significantly improved $\mathrm{H} / \mathrm{E}$ ratios which are beneficial when protecting soft steels and light alloys.
\end{abstract}

Keywords: nanocomposites; TiAlB coatings; TEM; XRD; XPS.

Running headline: Nanostructural studies of PVD TiAlB Coatings

\section{Introduction}

In recent years, researchers have become increasingly interested in nanostructured coatings including superhard (( $40 \mathrm{GPa})$ material systems such as "Ti-Si-N" and "Ti-Al-N"[i]. Most of the research on superhard coatings is focused on nitride and boride compounds, which in general are hard, stable materials with high melting points. However, hard ceramic coatings, such as TiN and $\mathrm{TiB}_{2}$, present a problem when deposited on relatively soft substrates due to the mismatch in elastic modulus (E) which can cause delamination of the coating under load.[ii] To improve the performance of ceramic based coatings, many possible combinations of ternary, and higher component systems are possible. For instance, the properties of TiN are significantly improved by adding $\mathrm{Al}$, which promotes oxidation resistance and increases hardness[iii] and the addition of $\mathrm{B}$ to $\mathrm{TiN}$ or $(\mathrm{Ti}, \mathrm{Al}) \mathrm{N}$ results in harder coatings exhibiting a multiphase structure consisting of $\mathrm{TiN}$, $\mathrm{TiB}_{2}$ and $\mathrm{BN}$ phases in agreement with the equilibrium phase diagram.[iv]

When considering boride based coatings without the addition of $\mathrm{N}$, surprisingly little work has been reported on the TiAlB system.[v] Coatings with a high $\mathrm{B}$ concentration have attracted interest due to the formation of the hard and stable $\mathrm{TiB}_{2}$ phase.[vi] However, $\mathrm{TiB}_{2}$ coatings are 
also brittle, and have a high elastic modulus (E 560 GPa) which when deposited on soft steels (E 200 GPa) can lead to early failure. The addition of Al to the Ti-B system can alleviate this problem by promoting a multiphase structure and a closer matching of the coating/substrate elastic properties. It has also been found that addition of $\mathrm{B}$ to Ti-Al based coatings leads to improved abrasive wear and grain refinement. ${ }^{3}$ It is thus of interest to investigate the TiAlB system in more detail. The aim of this investigation was to study the effect of different compositions on the structure and mechanical properties of sputter deposited TiAlB coatings.

\section{Experimental details}

TiAlB coatings were deposited onto AISI316 stainless steel substrates by co-sputtering from TiAl and $\mathrm{TiB}_{2}$ targets. Substrates were placed at 8 intervals across the centre of the chamber between the targets in order to obtain films with different compositions. Details of the vacuum chamber configuration are given elsewhere. ${ }^{5}$ Coatings were deposited for 70 minutes at a total Ar pressure of $0.45 \mathrm{~Pa}$, with a bias voltage of $-70 \mathrm{~V}$. The TiAl and $\mathrm{TiB}_{2}$ targets d.c. power density was 3.7 $\mathrm{W} / \mathrm{cm}^{2}$ and $11 \mathrm{~W} / \mathrm{cm}^{2}$ respectively and the final substrate temperature was $170^{\circ} \mathrm{C}$.

Both chemical and phase composition of the various coatings were determined by XPS, using a VG-Scientific Sigma Probe spectrometer employing a monochromated Al-K( source and a hemispherical analyser. A pass energy/step of $20 / 0.1 \mathrm{eV}$ was used for core level scans. Prior to analysis, samples were etched using a $3 \mathrm{keV}$ argon ion beam, until the oxygen peak reached a stable minimum value. Quantification of the data involved Shirley background subtraction and the use of instrument-modified Wagner sensitivity factors. The crystallographic structure and texture of the films were analysed by glancing-angle XRD (GAXRD), using $\mathrm{CuK}_{\text {( radiation at an incident }}$ angle of $1^{\circ}$. The $\mathrm{X}$-ray generator settings were $35 \mathrm{kV}$ and $30 \mathrm{~mA}$, the step angle being 0.2 (. TEM studies were performed using a Philips CM200 operated at $200 \mathrm{keV}$, employing a $\mathrm{LaB}_{6}$ filament. Specimen preparation involved grinding and polishing down the stainless steel substrate, followed by dimpling and ion beam thinning.

Hardness and elastic modulus measurements were carried out using a Hysitron Triboscope with Berkovich diamond indenter. The maximum applied load was $5 \mathrm{mN}$.

\section{Results and Discussion}

\subsection{Composition and chemical state (XPS)}

The sample compositions, determined from Ti 2p, B 1s and Al 2p peak areas are given in Table 1. The Ti concentration varies slightly (36-29 at.\%) from coating 1 (closest to the TiAl target) to coating 8 (closest to the $\mathrm{TiB}_{2}$ target), while the $\mathrm{B} / \mathrm{Al}$ ratio changes from 2 to 16.4 . The thickness of the coatings was $2 ? \mathrm{~m}(10 \%$. The location of coatings on the ternary Ti-Al-B phase diagram of Maxwell and Hellawell[vii] is shown in Fig. 1.

Fig. 2 shows the Al 2p, B 1s and Ti 2p XPS spectra for coatings 2, 4, 6 and 8. The main Al peak binding energy (BE) shifts to higher values (from 72.5 to $73 \mathrm{eV}$ ) as the $\mathrm{Al}$ content decreases from 21 at.\% (coating 1) to 4 at.\% (coating 8). This shift is due to bonding of $\mathrm{Al}$ with Ti for the $\mathrm{Al}$ rich coatings which leads to a decrease in $\mathrm{BE}$ of the $\mathrm{Al} 2 \mathrm{p}$ electrons.[viii] Hence, the value of $72.5 \mathrm{eV}$ for the Al-rich coatings possibly indicates formation of a Ti-Al phase as predicted by the phase diagram. The high $\mathrm{BE}$ peak in the $\mathrm{Al} 1$ s spectrum is attributed to Al-O bonding. 
The B 1s peak position corresponds to boride phase formation. The B 1s peak position measured on a $\mathrm{TiB}_{2}$ standard was found to be $188.0 \mathrm{eV}$. The $\mathrm{B} 1 \mathrm{~s}$ peak shifts from 187.6 to $187.8 \mathrm{eV}$ as the $\mathrm{B}$ content increases from 43 at. $\%$ to 67 at. $\%$. In $\mathrm{TiB}_{2}$, the $\mathrm{B} /$ metal stoichiometry is $2: 1$ and there is both Ti-B and B-B bonding.[ix] Coatings $1-4$ have a B/metal stoichiometry of approximately 1:1 and will be shown in section 3.2 to be amorphous. The higher number of metal nearest neighbourhood atoms (compared to $\mathrm{TiB}_{2}$ ) and amorphous nature of these coatings leads to the observed shift in $\mathrm{BE}$ of the $\mathrm{B}$ 1s peak to lower values (than $\mathrm{TiB}_{2}$ at $188 \mathrm{eV}$ ). The small peak observed at $189 \mathrm{eV}$ probably represents a small amount of $\mathrm{B}-\mathrm{O}$ bonding. Most probably, the strongest contribution to the $\mathrm{Al}-\mathrm{O}$ and $\mathrm{B}-\mathrm{O}$ components arises from adsorption of $\mathrm{O}$ onto the highly reactive etched TiAlB surface (even at the low partial pressures of $\mathrm{O}$ present in the UHV environment).

The Ti $2 \mathrm{p}_{3 / 2}$ peak shifts from $454.4 \mathrm{eV}$ (high Al content) to $454.7 \mathrm{eV}$ (low Al content). The Ti $2 \mathrm{p}_{3 / 2}$ peak position measured from the $\mathrm{TiB}_{2}$ standard was $454.8 \mathrm{eV}$. As with the $\mathrm{B} 1 \mathrm{~s}$, the peak shift to higher BEs observed here results from $\mathrm{Ti}$ atoms being bound to an increasing number of $\mathrm{B}$ atoms as the $\mathrm{B} / \mathrm{Al}$ ratio increases.

\subsection{Diffraction studies (XRD and TEM)}

The XRD patterns for coatings 2, 5, 7 and 8 are presented in Fig. 3. Spectra comprising of two broad peaks similar to that of coating 2 were observed for coatings 1 to 4 , indicating an $x$-ray amorphous structure. An increase in the spectral structure for coatings 5 and 6 is indicative of coatings being deposited with a crystalline fraction, most probably corresponding to nanocrystsalline $\mathrm{TiB}_{2}$. Coatings 7 and 8 exhibit diffraction peaks clearly identifiable as $\mathrm{TiB}_{2}$.

Grain sizes estimates were made adopting the single line method described by Kiejser ${ }^{[x]}$ based on the least-squares fitting of broadened peaks to a pseudo-Voigt function. Grain size estimates for coating 8 are $(6 \mathrm{~nm}$ in the 001 direction, $(2 \mathrm{~nm}$ in the 101 direction, and $(1.5 \mathrm{~nm}$ in the 100 direction, while for coating 7 estimates are $(3.5 \mathrm{~nm}$ in the 001 direction, $(1.5 \mathrm{~nm}$ in the 101 direction, and (1 nm in the 100 direction. For coatings 5 and 6, peak overlap prohibits a clear fit, but the structure would consist of even smaller crystallites than sample 7 (perhaps only 1 or 2 $\mathrm{nm})$.

Coatings were investigated by TEM and the selected area diffraction (SAD) patterns for coatings 2, 4, 6 and 8 are shown in Fig. 4. Coatings 2 and 4 show a broad diffused halo and are amorphous. SAD patterns for coatings 6 and 8 exhibited up to 5 and 9 distinguishable rings respectively, indicative of a nanocrystalline material. Variations in the diffracted intensity of the rings indicate some degree of crystallographic texture. Rings can be indexed to reflections of $\mathrm{TiB}_{2}$, this being the only crystalline phase present, in agreement with the XRD results.

Fig. 5 displays dark field (DF) images for coatings 6 and 8, formed from the $\mathrm{TiB}_{2}$ (101) and (100) reflections. The grain sizes seen in the (101) DF images appear to be slightly larger than those in the (100) DF images, in agreement with the XRD grain size estimations. The nanostructure of coating 6 is very fine with average nanocrystallite sizes of $(1-1.5 \mathrm{~nm}$; for coating 8 , larger nanocrystallites are observed, with average grain sizes of $(2.5 \mathrm{~nm}$, again similar to the XRD grain size values. A high resolution (HR) micrograph for coating 8 is also given in Fig. 5. The d-spacing for two of the individual nanocrystals (measured using contrast line scans), were $0.203 \mathrm{~nm}$ and 
$0.268 \mathrm{~nm}$, corresponding to (101) and (100) planes in the $\mathrm{TiB}_{2}$ phase respectively.

\subsection{Hardness and Elastic Modulus}

Nanoindentation data taken at a $5 \mathrm{mN}$ load are shown in Fig. 6. An increase in both hardness $(\mathrm{H})$ and elastic modulus $(\mathrm{E})$ values is observed from coating $1(\mathrm{H}=14 \mathrm{GPa} ; \mathrm{E}=196 \mathrm{GPa})$ to coating $8(\mathrm{H}=31 \mathrm{GPa} ; \mathrm{E}=330 \mathrm{GPa})$. The $\mathrm{H} / \mathrm{E}$ values also increase from 0.07 to 0.09 (Fig. 6 insert).

The observed increase in $\mathrm{H}$ (and $\mathrm{E}$ ) with increasing $\mathrm{B} / \mathrm{Al}$ ratio can be explained by an increasing fraction of the hard $\mathrm{TiB}_{2}$ phase within the coating and the small nanocrystalline $\mathrm{TiB}_{2}$ grains hindering dislocation multiplication and movement. The elastic modulus of these nanostructured coatings reaches a maximum of $320 \mathrm{GPa}$ for a coating which according to the phase diagram will have a $\mathrm{TiB}_{2}$ content of $(83 \%$. This compares to a much higher elastic modulus of $560 \mathrm{GPa}$ for bulk $\mathrm{TiB}_{2}$. These coatings thus exhibit a high hardness (of up to $30 \mathrm{GPa}$ ) together with an elastic modulus similar to that of the steel substrate and are expected to show excellent properties in applications requiring high impact and abrasive wear resistance.

\section{Conclusion}

The structure of sputtered TiAlB coatings deposited at low temperatures $\left(170^{\circ} \mathrm{C}\right)$ varies as a function of $\mathrm{B} / \mathrm{Al}$ ratio. Coatings with low $\mathrm{B} / \mathrm{Al}$ ratios $(<6)$ have an amorphous structure. Increasing $\mathrm{B} / \mathrm{Al}$ ratios resulted in coatings with increasing crystallinity, $\mathrm{TiB}_{2}$ being the only crystalline phase. The average grain size increases from $(1 \mathrm{~nm}$ for coatings with $\mathrm{B} / \mathrm{Al}=9$, to $(2.5$ $\mathrm{nm}$ for coatings with $\mathrm{B} / \mathrm{Al}$ ratio $=16$. Hardness, elastic modulus and $\mathrm{H} / \mathrm{E}$ ratio increase with higher $\mathrm{B} / \mathrm{Al}$ ratios. The high $\mathrm{H} / \mathrm{E}$ ratio of the nanocomposite coatings will improve their ability to accommodate substrate strain (improving impact and wear resistance) when deposited on soft steels and light alloys. 


\section{Tables}

Table 1. Chemical composition of TiAlB coatings 1 (closest to the TiAl target) to coating 8 (closest to the $\mathrm{TiB}_{2}$ target) determined by XPS.

\begin{tabular}{|c|c|c|c|c|}
\hline Coating & Ti at. $\%$ & $B$ at. $\%$ & Al at. $\%$ & $\mathrm{~B} / \mathrm{Al}$ \\
\hline 1 & 35.9 & 42.8 & 21.3 & 2.0 \\
\hline 2 & 36.8 & 47.5 & 15.7 & 3.0 \\
\hline 3 & 35.3 & 51.9 & 12.8 & 4.0 \\
\hline 4 & 33.7 & 54.9 & 11.4 & 4.8 \\
\hline 5 & $\mid 31.2$ & 59.5 & 9.3 & 6.4 \\
\hline 6 & 30.5 & 62.5 & 7.0 & 8.9 \\
\hline 7 & | 28.2 & 67.3 & 4.5 & 14.9 \\
\hline 8 & 28.6 & 67.3 & 4.1 & 16.4 \\
\hline
\end{tabular}




\section{Figures}

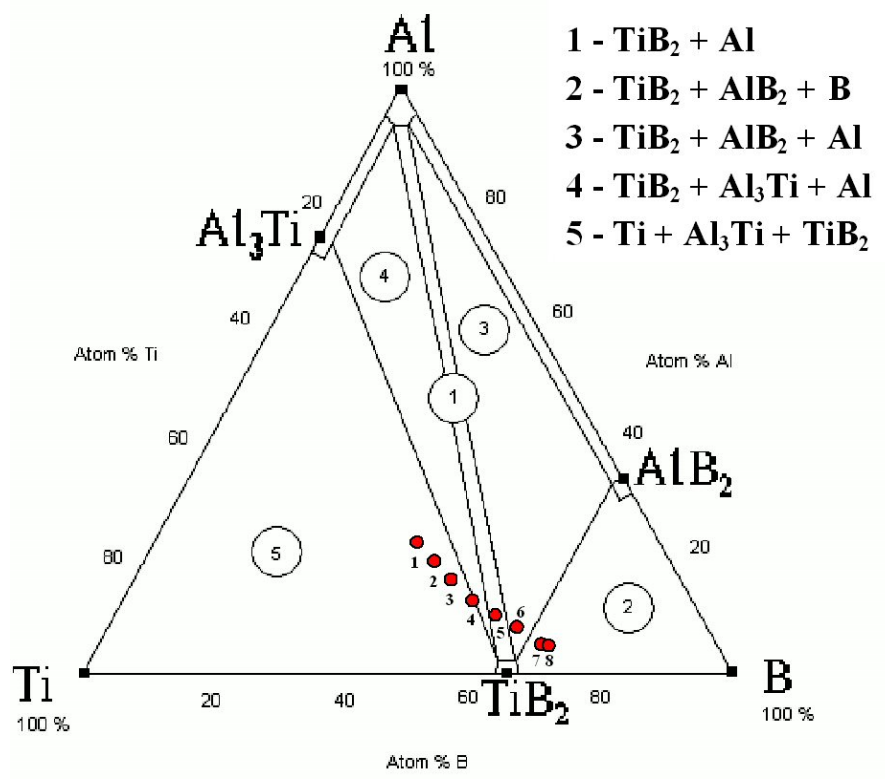

Fig.1. Ti-Al-B phase diagram showing the relevant phase regions and location of the deposited TiAlB coatings (taken from [7]). 

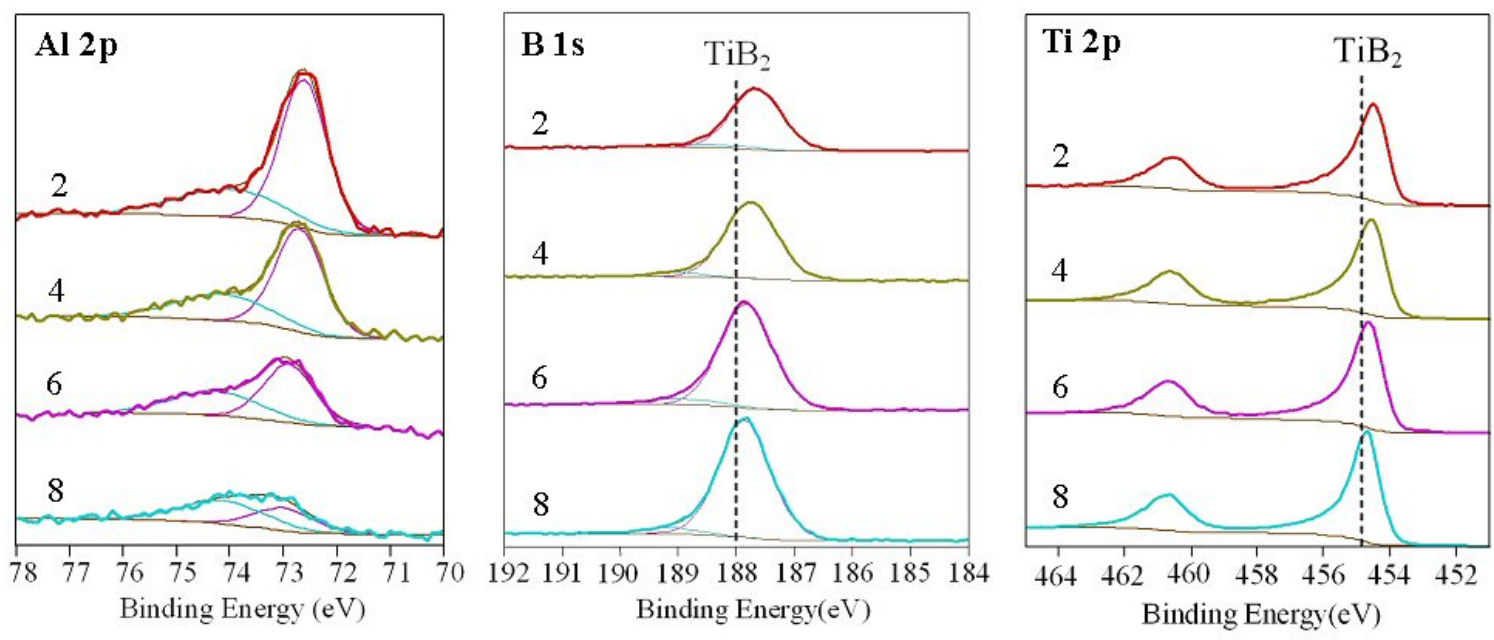

Fig 2. Al 2p, B 1s and Ti 2p XPS narrow scan spectra of TiAlB coatings 2, 4, 6 and 8, with corresponding $\mathrm{B} / \mathrm{Al}$ ratios of 3.0, 4.8, 8.9 and 16.4. 


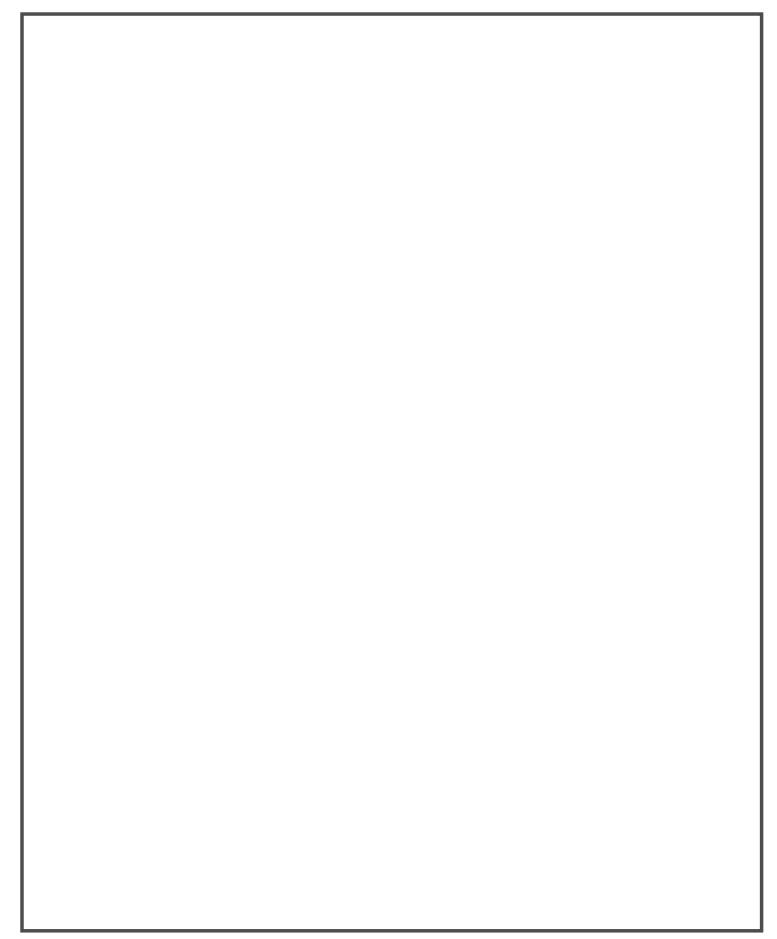

Fig. 3. XRD spectra of TiAlB coatings 2, 5, 7, and 8. The main reflections for $\mathrm{TiB}_{2}$ (JCPDS No. 35-0741) are also shown. 


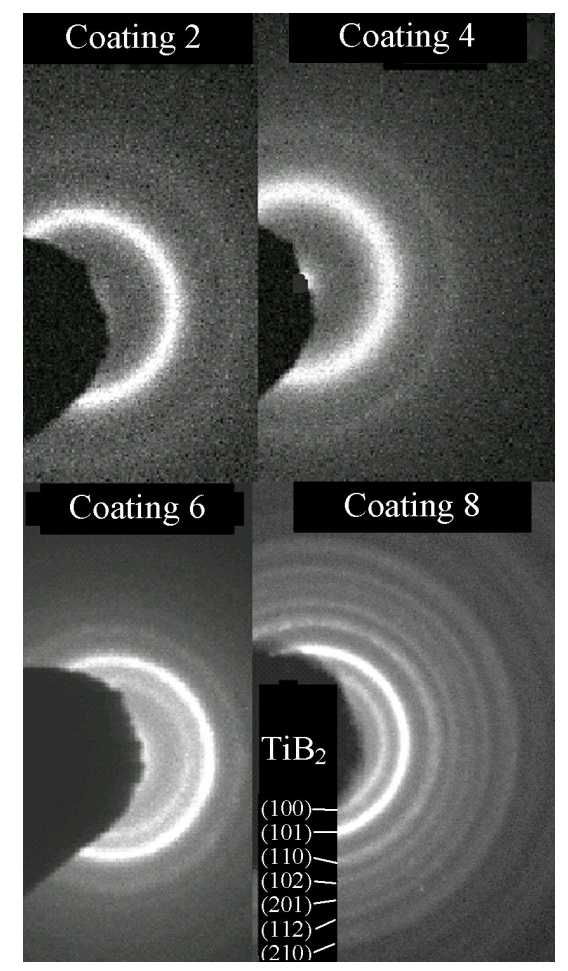

Fig. 4. TEM-SAD diffraction patterns for coatings 2, 4, 6 and 8.

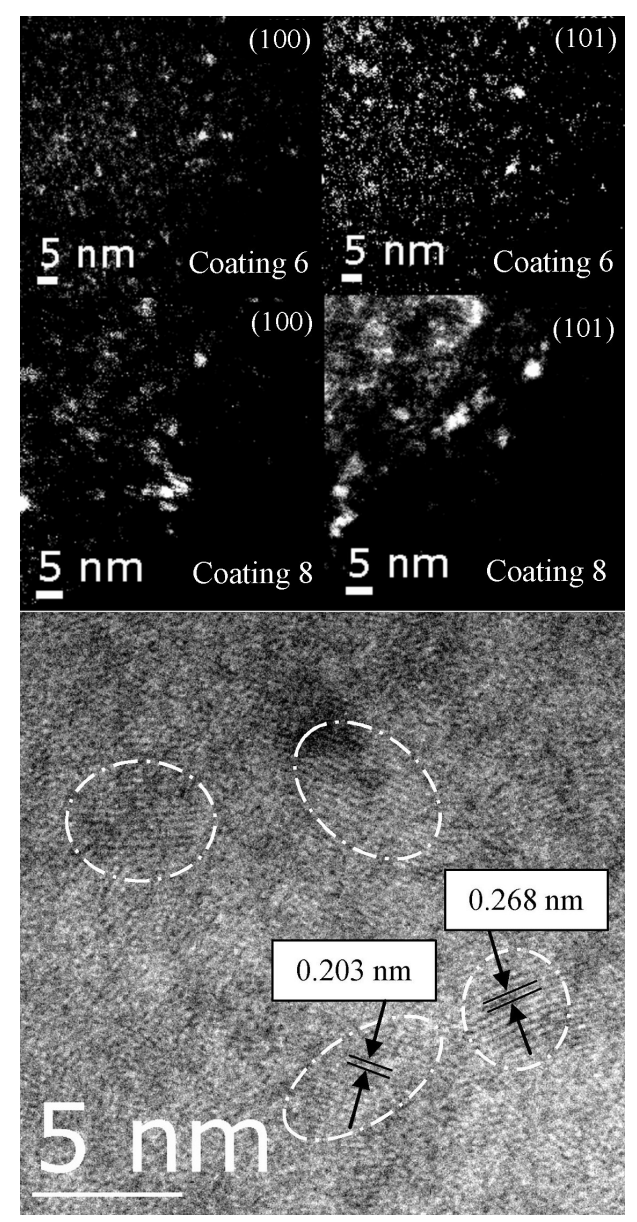


Fig. 5. Top - plan view dark field TEM micrographs obtained from (100) and (101) reflections of coatings 6 and coating 8. Bottom - HREM image of coating 8 . 


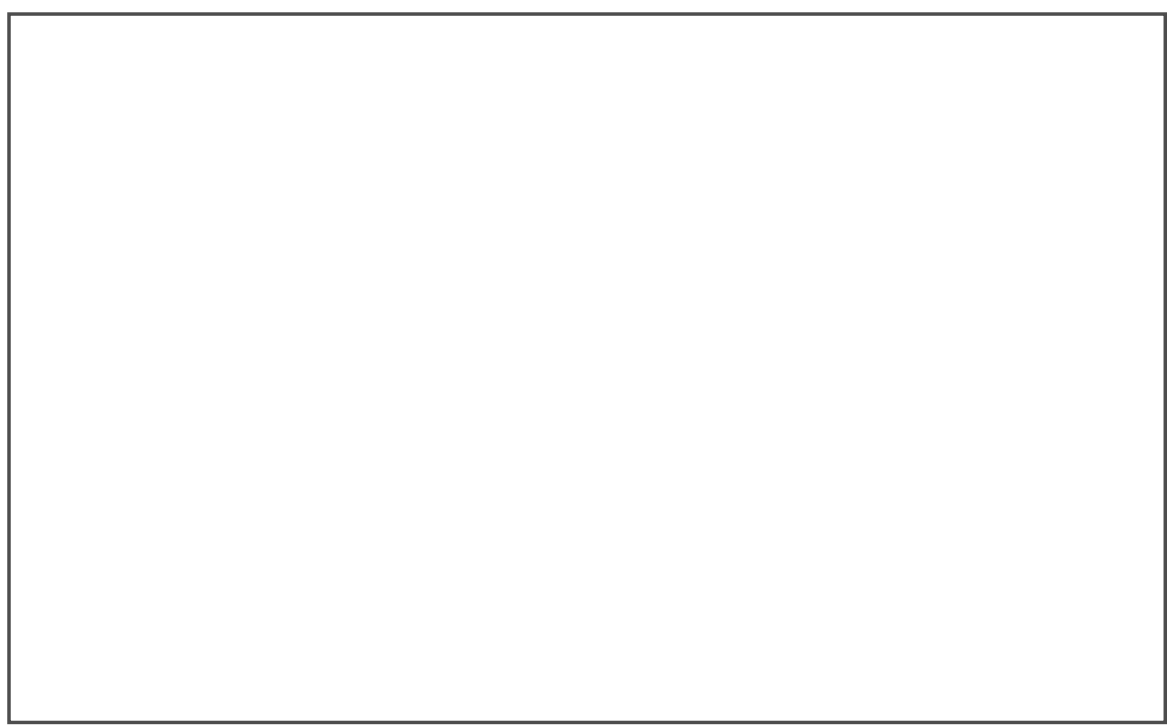

Fig. 6. Hardness and elastic modulus values for coatings 1-8. 


\section{References}

\section{[i]. S. Veprek, M.G.J. Veprek-Heijman, P. Karvankoza, J. Prochazka, Thin Solid Films,}

2005; 476: 1.

[ii] A. Leyland, A. Matthews, Surf. Coat. Technol. 2004; 317: 177.

[iii] S. PalDey, S.C. Deevi, Material Science and Engineering, 2003; A342: 58.

[iv] M.A. Baker, S. Klose, C. Rebholz, A. Leyland, A. Matthews, Surf. Coat. Technol. 2002; 151-152: 338.

[v] C. Rebholz, A. Leyland, J.M. Schneider, A.A. Voevodin, A. Matthews, Surf. Coat. Technol. 1999; 120-121: 412.

[vi] P. Losbichler, C.Mitterer, Surf. Coat. Technol. 1997; 97: 567.

[vii] I. Maxwell, A. Hellawell, Metall. Trans. 1972; 3: 1487.

[viii] S. Diplas, J.F. Watts, P. Tsakkiropoulos, G. Shao, G. Beamson, J.A.D. Matthew, Surf. Interface Anal. 2001; 31 : 734.

[ix] V.M. Anishchik, K.N. Dorozhkin, Phys. Stat. Sol. B 1990; 190: 173.

[x] T.H. de Keijser, E.J. Mittemeijer and H. C. Rozendaal, J. Appl. Cryst. 1983; 16: 309.

\section{Coating 8}

Coating 6

Coating 4

Coating 2

7,8

6

2

1 